\title{
Role of Composition and Size of Cobalt Ferrite Nanocrystals in the Oxygen Evolution Reaction
}

\author{
Kalapu Chakrapani, ${ }^{[a]}$ Georg Bendt, ${ }^{[a]}$ Hamidreza Hajiyani, ${ }^{[b]}$ Ingo Schwarzrock, ${ }^{[a]}$ Thomas \\ Lunkenbein, ${ }^{[c]}$ Soma Salamon, ${ }^{[b]}$ Joachim Landers, ${ }^{[b]}$ Heiko Wende, ${ }^{[b]}$ Robert Schlögl, ${ }^{[c, d]}$ Rossitza \\ Pentcheva, ${ }^{[b]}$ Malte Behrens, ${ }^{[a, e] *}$ Stephan Schulz ${ }^{[a] *}$
}

\begin{abstract}
Sub-10 nm CoFe ${ }_{2} \mathrm{O}_{4}$ nanoparticles with different sizes and various compositions obtained by (partial) substitution of $\mathrm{Co}$ with $\mathrm{Ni}$ cations have been synthesized using a one-pot method from organic solutions by decomposition of metal acetylacetonates in the presence of oleyl amine. The electro catalytic activity of $\mathrm{CoFe}_{2} \mathrm{O}_{4}$ towards the oxygen evolution reactions (OER) is clearly enhanced with smaller size $\left(3.1 \mathrm{~nm}\right.$ ) of the $\mathrm{CoFe}_{2} \mathrm{O}_{4}$ nanoparticles (as compared to 4.5 and $5.9 \mathrm{~nm}$ ). In addition, the catalytic activity is improved by partial substitution of $\mathrm{Co}$ with $\mathrm{Ni}$, which also leads to a higher degree of inversion of the spinel structure. Theoretical calculations explain the positive catalytic effect of $\mathrm{Ni}$ by lower binding energy differences between adsorbed $\mathrm{O}$ and $\mathrm{OH}$ as compared to pure cobalt or nickel ferrites, resulting in higher OER activity. $\mathrm{Co}_{0.5} \mathrm{Ni}_{0.5} \mathrm{Fe}_{2} \mathrm{O}_{4}$ exhibited a low overpotential of $\sim 340 \mathrm{mV}$ at $10 \mathrm{~mA} \mathrm{~cm}^{-2}$, a smaller Tafel slope of $51 \mathrm{mV} \mathrm{dec}{ }^{-1}$ and stability over $30 \mathrm{~h}$. The unique tunability of these $\mathrm{CoFe}_{2} \mathrm{O}_{4}$ nanocrystals provide great potential for their application as an efficient and competitive anode material in the field of electrochemical water splitting as well as for systematic fundamental studies aiming at understanding the correlation of composition and structure with performance in electrocatalysis.
\end{abstract}

\section{Introduction}

The high energy demand of water electrolysers mostly accrues from the sluggish kinetics of the oxygen evolution reaction (OER), which remains limiting even for the best electrocatalysts, such as $\mathrm{RuO}_{2}$ or $\mathrm{IrO}_{2}$, which in addition are scares and of high cost. ${ }^{1}$ Many efforts have been made to develop highly active, durable and low cost alternatives such as transition metal chalcogenides,

[a] Dr. Kalapu Chakrapani, Georg Bendt, Ingo Schwarzrock, Prof. Dr. Malte Behrens, ${ }^{*}$ Prof. Dr. Stephan Schulz ${ }^{*}$, Faculty of Chemistry, Inorganic Chemistry, and Center for Nanointegration DuisburgEssen (CENIDE), University of Duisburg-Essen, Universitätsstr. 7 , 45114 Essen, Germany.

[b] Dr. Hamidreja Hajiyani, Soma Salamon, Joachim Landers, Prof. Dr Heiko Wende, Prof. Dr. Rossitza Pentcheva Faculty of Physics and Center for Nanointegration Duisburg-Essen (CENIDE), University of Duisburg-Essen, Lotharstr. 1, 47057 Duisburg, Germany

[c] Dr. Thomas Lunkenbein, Prof. Dr. Robert Schlögl, Fritz-HaberInstitute of the Max-Planck-Society, Department of Inorganic Chemistry, Faradayweg 4-6, 14195 Berlin, Germany.

[d] Prof. Dr. Robert Schlögl, MPI for Chemical Energy Conversion Stiftstrasse 34 - 36 / D - 45470 Mülheim an der Ruhr, Germany

[e] Prof. Dr. Malte Behrens, Ertl Center for Electrochemistry and Catalysis of the Gwangju Institute of Science (GIST), 123 Cheomdan-gwagiro (Oryang-dong), Buk-gu, Gwangju 500-712, South Korea

Prof. Dr. Stephan Schulz, Phone: +49 (0)201-183 4635; e-mail: stephan.schulz@uni-due.de and Prof. Dr. Malte Behrens, Phone: +49 (0)201-183 3684; e-mail: malte.behrens@uni-due.de. hydroxides and phosphides. ${ }^{2-6}$ In basic environment, first-row transition metal oxides of the perovskite and spinel types are very promising candidates due to their earth abundance and excellent electrochemical activity. The catalytic performance in the OER generally depends on the number of active sites and the adsorption energies of reactive intermediates. It was observed in mixed metal oxides to strongly vary with their chemical composition and electronic structure. ${ }^{6}$ First causative relationships between structure and composition with electrocatalysis have been established for perovskites with the help of computational chemistry. ${ }^{6 \mathrm{~d}}$

In this context, spinel-type transition metal ferrites $\left(\mathrm{M}^{\prime \prime} \mathrm{Fe}^{\mathrm{III}}{ }_{2} \mathrm{O}_{4}\right)$ with inverse spinel structure are another interesting materials family for such fundamental studies in oxygen electrochemistry. ${ }^{7}$ These spinels are of special interest due to the easiness of multiple substitutions of the transition metal cations, which enables changes in important properties such as conductivity and catalytic activity ${ }^{8}$ and, thus, allows for a fine-tuning of the electrocatalytical properties. In many cases, a better performance of multinary mixed oxides compared to a simple mixture of the corresponding single oxides has been observed, while the exact properties depend on the nature and stoichiometry (composition) of the metal ions in the final mixed phase. ${ }^{8}$

Spinel ferrite nanocrystals are of interest for applications in the field of electromagnetic devices and their properties can be significantly affected by either tuning the size or the cation substitution. ${ }^{9}$ Most of the research on spinel ferrites in electrochemistry addressed their potential application in energy storage devices as an electrocatalyst for oxygen electrochemistry. ${ }^{7,8,10}$ Recently, the inversion parameter of the spinel structure has been proposed as yet another parameter relevant in the oxygen reduction electrocatalysis of ferrites. ${ }^{9}$ Due to these different parameters such as structure, composition and size and their complex interplay, the tuning of the electrocatalytic performance of transition metal spinels has remained mostly empirical.

While much work has been done on spinel cobaltite $\mathrm{M}_{\mathrm{x}} \mathrm{Co}_{3-\mathrm{x}} \mathrm{O}_{4}$ as OER catalysts ${ }^{5 a}$, there are only few studies on spinel cobalt ferrites that focus on the cation substitution concept and the sizedependence of the electrocatalytic properties. Such effort requires a synthetic approach allowing for the independent variation of these parameters, a detailed structural analysis and a theoretical simulation in relation to the electrochemical measurements with the aim to contribute to a rational design of ferrite OER catalysts. We herein report a facile one-pot synthesis of $\mathrm{CoFe}_{2} \mathrm{O}_{4}$ nanoparticles with different sizes between 3 and $6 \mathrm{~nm}$ and various compositions $\mathrm{Co}_{x} \mathrm{Ni}_{1-x} \mathrm{Fe}_{2} \mathrm{O}_{4}$ with $\mathrm{x}$ varying from 0.25 to 1 , by utilizing the one-pot high-temperature organic solutionphase chemical decomposition method. ${ }^{11}$ The resulting nanomaterials have been thoroughly characterized and their electrocatalytic activity towards the OER was demonstrated by 
using various electrochemical techniques. In addition, also $\mathrm{Co}_{x} \mathrm{M}_{1}$. ${ }_{x} \mathrm{Fe}_{2} \mathrm{O}_{4}$ nanoparticles with $\mathrm{x}=0.5$ and $\mathrm{M}=\mathrm{Mn}, \mathrm{Fe}, \mathrm{Zn}$ ) were synthesized proving the versatility of the synthesis method for substitution in the cationic sub-lattice of spinel ferrites. Only the resulting materials with $\mathrm{M}=\mathrm{Ni}$ are discussed here in detail, while information on the other transition metal substituents are provided in the Supporting Information (SI).
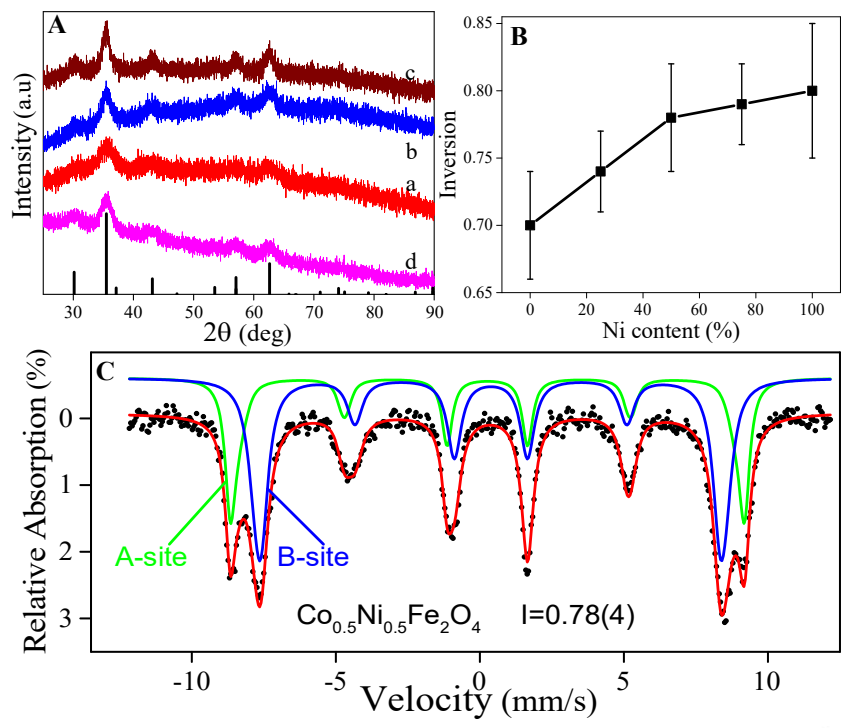

Figure 1. Characterization of cobalt ferrite nanocrystals. A) XRD of $\mathrm{CoFe}_{2} \mathrm{O}_{4}$ nanoparticles with different sizes as-prepared at (a) $200{ }^{\circ} \mathrm{C}$, (b) $250{ }^{\circ} \mathrm{C}$, (c) $300{ }^{\circ} \mathrm{C}$ and (d) $\mathrm{Co}_{0.5} \mathrm{Ni}_{0.5} \mathrm{Fe}_{2} \mathrm{O}_{4}$ nanoparticles. B) Degree of structural inversion as a function of $\mathrm{Ni}$ content. C) Mössbauer spectrum for $\mathrm{Co}_{0.5} \mathrm{Ni}_{0.5} \mathrm{Fe}_{2} \mathrm{O}_{4}$ nanoparticles recorded at $4.3 \mathrm{~K}$ in an applied magnetic field of $5 \mathrm{~T}$ parallel to the gamma ray propagation direction.

\section{Results and Discussion}

\section{Materials Characterization}

A simple one-pot organic solution-phase chemical decomposition method was employed to synthesize pure $\mathrm{CoFe}_{2} \mathrm{O}_{4}$ and substituted $\mathrm{Co}_{x} \mathrm{Ni}_{1-x} \mathrm{Fe}_{2} \mathrm{O}_{4}$ nanoparticles by thermal decomposition of the corresponding amounts of bivalent metal acetylacetonates and $\mathrm{Fe}(\mathrm{acac})_{3}$ in oleylamine, to reach $\mathrm{x}$ values of $0,0.25,0.50$, or 0.75 . Figure $1 \mathrm{~A}(\mathrm{a}-\mathrm{c})$ shows the typical $\mathrm{XRD}$ patterns of as-synthesized $\mathrm{CoFe}_{2} \mathrm{O}_{4}$ nanoparticles obtained at different reaction temperatures. All observed Bragg peaks at $2 \theta$ values of $30.2^{\circ}, 35.6^{\circ}, 43.4^{\circ}, 57.2^{\circ}, 62.6^{\circ}$ corresponds to the (220), (311) (400), (511) and (440) lattice plane d-spacings of cubic spinel-type $\mathrm{CoFe}_{2} \mathrm{O}_{4}$ phase (PDF 22-1086) with $\mathrm{a}=8.3919$ $\AA$. The diffraction peaks show strong broadening due the nanosized nature of the crystalline domains and the peaks sharpen slightly as the reaction temperature was increased from $200^{\circ} \mathrm{C}$ to $300^{\circ} \mathrm{C}$. This indicates an increase in the crystalline domain size, suggesting that the size of the as-synthesized $\mathrm{CoFe}_{2} \mathrm{O}_{4}$ nanoparticles can be tuned by controlling the reaction temperature. This assumption was confirmed by TEM (see below). The crystallite sizes are estimated to range from 3.5 and 5.1 to $7.2 \mathrm{~nm}$ based on the Scherrer equation. The partial substitution of $\mathrm{Ni}$ is not clearly visible in XRD pattern due to the similar ionic radii supporting an isomorphous substitution of cobalt in $\mathrm{Co}_{0.5} \mathrm{Ni}_{0.5} \mathrm{Fe}_{2} \mathrm{O}_{4}$ (Figure $1 \mathrm{~A}$ and Figure $\mathrm{S} 1, \mathrm{SI}$ ). No additional peaks pointing to the presence of impurities or other phases such as elemental metals or other oxides are visible in the diffractograms.

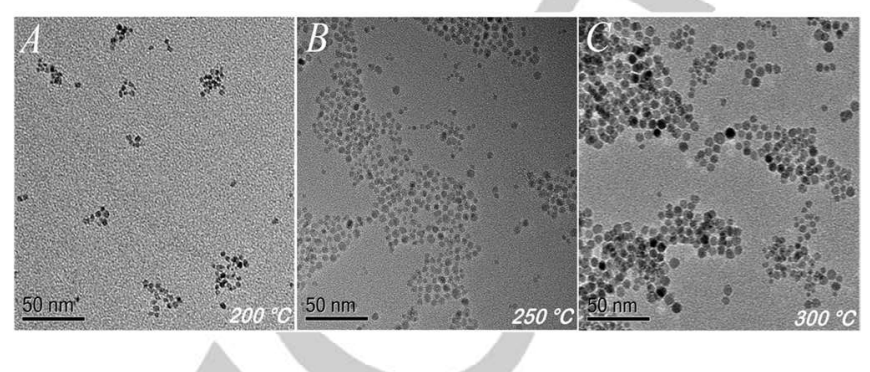

Figure 2. TEM characterization of the morphology of the $\mathrm{CoFe}_{2} \mathrm{O}_{4}$ nanoparticles synthesized at $200^{\circ} \mathrm{C}(\mathrm{A}) ; 250^{\circ} \mathrm{C}(\mathrm{B})$ and $300^{\circ} \mathrm{C}(\mathrm{C})$.

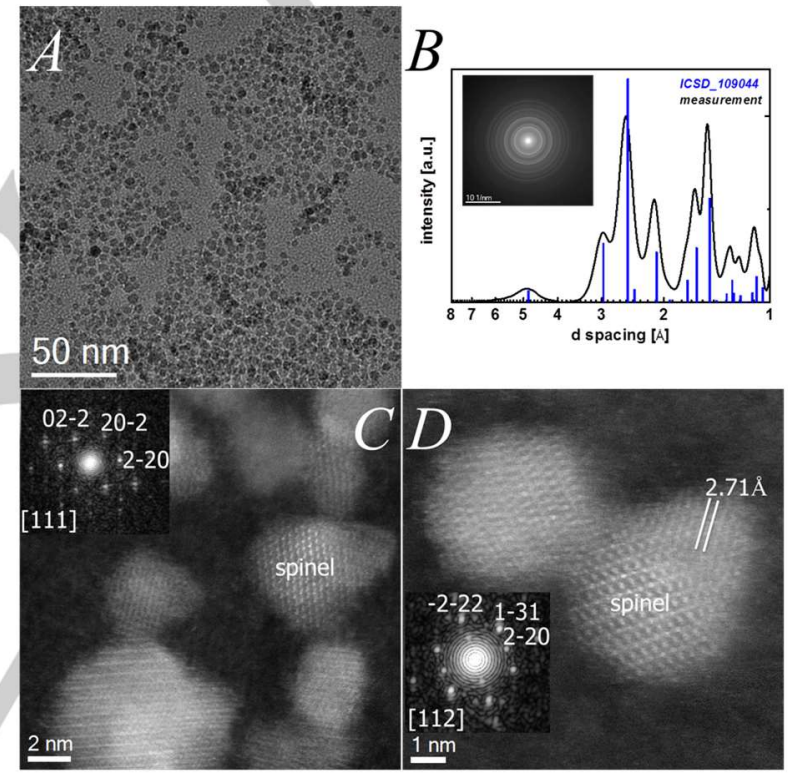

Figure 3. TEM investigation of $\mathrm{Co}_{0.5} \mathrm{Ni}_{0.5} \mathrm{Fe}_{2} \mathrm{O}_{4}$ nanoparticles as synthesized at $250{ }^{\circ} \mathrm{C}$. (A) Overview image of the nanoparticles, (B) line profile of the corresponding SAED (inset). (C) and (D) High resolution HAADF-STEM micrographs. The insets are the FFT patterns of the particles labelled with spinel.

The degree of inversion of the spinel structure, i.e., the distribution of the iron cations over the tetrahedral and octahedral sites was determined by Mössbauer spectroscopy. Mössbauer spectra for samples $\mathrm{Co}_{x} \mathrm{Ni}_{1-x} \mathrm{Fe}_{2} \mathrm{O}_{4}$, with $(\mathrm{x}=0 ; 0.25 ; 0.5 ; 0.75 ; 1)$, were recorded at room temperature and at $4.3 \mathrm{~K}$ under an applied magnetic field of $5 \mathrm{~T}$ shown in Figure S2-S3 (SI). Exemplarily, an in-field spectrum of $\mathrm{Co}_{0.5} \mathrm{Ni}_{0.5} \mathrm{Fe}_{2} \mathrm{O}_{4}$ is displayed in Figure $1 \mathrm{C}$. All room temperature spectra display a superparamagnetic doublet (green). For $x>0$, an additional magnetically blocked sextet (blue) is visible, with its spectral area increasing upon higher Co content. The inversion parameter was determined by using low temperature high-field measurements. Two magnetically ordered sextets were utilized to evaluate the data, corresponding to the $A$ (tetrahedral) and B (octahedral) sites occupied by the Fe ions. The different ratios of $A$ to $B$ site spectral areas from which the cation distribution were observed and, therefore, the inversion parameter can be calculated. ${ }^{12 a}$ Assuming similar Debye-Waller- 
factors of $A$ and $B$ site at $5 \mathrm{~K},{ }^{12 b}$ we yield a degree of inversion of 0.70 (4) for $\mathrm{CoFe}_{2} \mathrm{O}_{4}$ that rises to $0.78(4)$ for $\mathrm{Co}_{0.5} \mathrm{Ni}_{0.5} \mathrm{Fe}_{2} \mathrm{O}_{4}$, followed by a slower rise to $0.80(5)$ for $\mathrm{NiFe}_{2} \mathrm{O}_{4}$, as shown in Figure $1 \mathrm{~B}$. These result indicates a predominantly inverse spinel structure for all five $\mathrm{Co}_{x} \mathrm{Ni}_{1-\mathrm{x}} \mathrm{Fe}_{2} \mathrm{O}_{4}$ ferrites as expected for the bulk materials. The degree of inversion is lower than unity and such deviations from perfect inversion have been observed previously for particles in the low nanometer range. ${ }^{12 c}$ The increasingly inverse spinel structure that was detected for higher Ni content is consistent with our density functional theory with Hubbard $U$ $(\mathrm{DFT}+U)$ calculations showing that the inverse spinel is preferred by $0.11 \mathrm{eV} /$ f.u. for $\mathrm{CoFe}_{2} \mathrm{O}_{4}$ and $0.45 \mathrm{eV} /$ f.u. for $\mathrm{NiFe}_{2} \mathrm{O}_{4}$ over the normal spinel, which is in agreement with previous investigations. $^{12 \mathrm{~d}}$
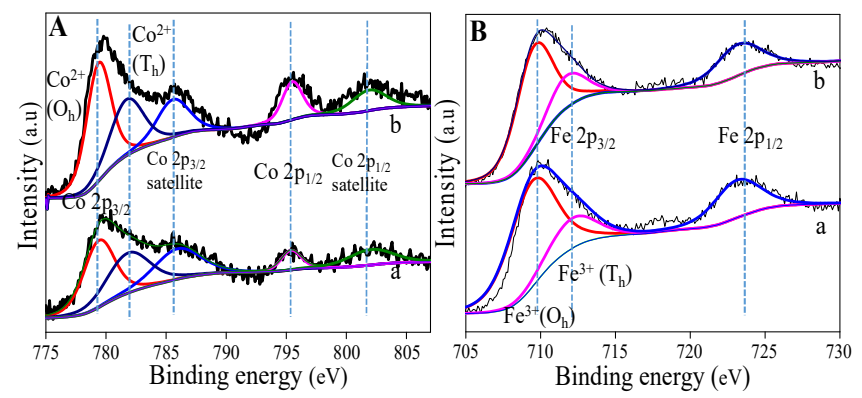

Figure 4. XPS spectra of (A) Co 2p; (B) Fe 2p regions of (a) $\mathrm{CoFe}_{2} \mathrm{O}_{4}$ and (b) $\mathrm{Co} 0.5 \mathrm{Ni}_{0.5} \mathrm{Fe}_{2} \mathrm{O}_{4}$ nanoparticles.

To gain further insight into the size of the $\mathrm{CoFe}_{2} \mathrm{O}_{4}$ nanoparticles obtained at different reaction temperatures, transmission electron microscopy (TEM) images were recorded (Figure 2). In good agreement with the XRD peak width analysis, an increase in particle size from an average value of $3.1 \mathrm{~nm}$ to $5.9 \mathrm{~nm}$ with increasing reaction temperature is clearly visible in the statistical evaluation of the particle size distribution (Figure $\mathrm{S} 4, \mathrm{SI}$ ). Furthermore, the images confirm that the utilization of the capping agent during synthesis leads to almost monodisperse nanoparticles at low temperatures $\left(200\right.$ and $\left.250{ }^{\circ} \mathrm{C}\right)$, while those obtained at $300{ }^{\circ} \mathrm{C}$ showed a slightly broader size-distribution (Figure S4, SI). EDX spectroscopy confirmed the presence of Co, $\mathrm{Fe}$ and the substituent $3 \mathrm{~d}$ metal cations in the nanoparticles (Figure S5-S9, SI).

In addition, a high resolution TEM (HRTEM) study was conducted on $4 \mathrm{~nm}$-sized $\mathrm{Co}_{0.5} \mathrm{Ni}_{0.5} \mathrm{Fe}_{2} \mathrm{O}_{4}$ nanoparticles obtained at $250{ }^{\circ} \mathrm{C}$. Figure $3 \mathrm{~A}$ displays a representative overview image the $\mathrm{Ni}$ substituted spinel showing that the substitution did not have a major effect on particle size or morphology. The profile obtained by the integration of the corresponding SAED pattern in Figure 3B indicates again the presence of a spinel-type oxide and no additional phases. Accordingly, the HRTEM image of the $\mathrm{Co}_{0.5} \mathrm{Ni}_{0.5} \mathrm{Fe}_{2} \mathrm{O}_{4}$ nanoparticles shows a lattice fringe distance of $0.271 \mathrm{~nm}$, which likely corresponds to a spinel phase rather than to $\mathrm{NiO}$, for which no indication was found in SAED or XRD (Figure 3D). The atomic resolution high angle annular dark-field scanning trans mission electron microscopy (HAADF-STEM) images (Figure 3C,D) reveal a high crystallinity for the substituted spinels. The electron microscope investigation thus confirms in agreement with integral XRD results the formation of a pure spinel phase for $\mathrm{Co}_{0.5} \mathrm{Ni}_{0.5} \mathrm{Fe}_{2} \mathrm{O}_{4}$.

Figure 4 shows the XP spectra of $\mathrm{CoFe}_{2} \mathrm{O}_{4}$ and $\mathrm{Co}_{0.5} \mathrm{Ni}_{0.5} \mathrm{Fe}_{2} \mathrm{O}_{4}$ and the observed binding energies which are in good agreement with those expected for spinel ferrites. ${ }^{13}$ The signals at binding energies of $779.6 \mathrm{eV}$ and $795.1 \mathrm{eV}$ correspond to $\mathrm{Co} 2 \mathrm{p}_{3 / 2}$ and $\mathrm{Co}$ $2 p_{1 / 2}$ of $\mathrm{Co}^{2+}$ ions along with the satellite peak of Co $2 p_{3 / 2}$ at 785.9 $\mathrm{eV}$ (Figure 1D) consistent with reported values. ${ }^{13 a}$ The relative intensity of the core level peaks assigned to octahedral sites at the surface increased at the expense of tetrahedrally coordinated $\mathrm{Co}$ in $\mathrm{Co}_{0.5} \mathrm{Ni}_{0.5} \mathrm{Fe}_{2} \mathrm{O}_{4}$. This trend is consistent with the inversion parameter of the bulk structure, which has indicated the presence of both octahedrally and tetrahedrally coordinated bivalent cations and a stronger inversion in the presence of $\mathrm{Ni}$. The Fe $2 p$ spectra displayed Fe $2 p_{3 / 2}$ and $\mathrm{Fe} 2 \mathrm{p}_{1 / 2}$ peaks at $710.9 \mathrm{eV}$ and $723.9 \mathrm{eV}$, respectively, correspond to $\mathrm{Fe}^{3+}$ oxidation state (figure $4 \mathrm{~B}$ ). The satellite peak of $\mathrm{Fe} 2 \mathrm{p}_{3 / 2}$ observed at $\mathrm{B}$. $\mathrm{E}$ value of $8 \mathrm{eV}$ higher than main peak is also consistent with $\mathrm{Fe}^{3+}$ and similar values were reported earlier. ${ }^{13}$ The $O 1$ s signals show peaks at 529.6 and $531.2 \mathrm{eV}$ in which the first peak is attributed to the contribution of the lattice oxygen shown in figure S10, SI. However, the exact assignment of the higher binding energy peaks is rather complex as numerous factors such as surface defects, impurities, or chemisorbed oxygen species. The Ni2p shows peak positions at 855.1 and $872.3 \mathrm{eV}$ consistent with the presence of $\mathrm{Ni}^{2+}$ along with asymmetric shoulders likely due to the presence of small amount of hydroxide on the surface (figure S10, $\mathrm{SI})$.
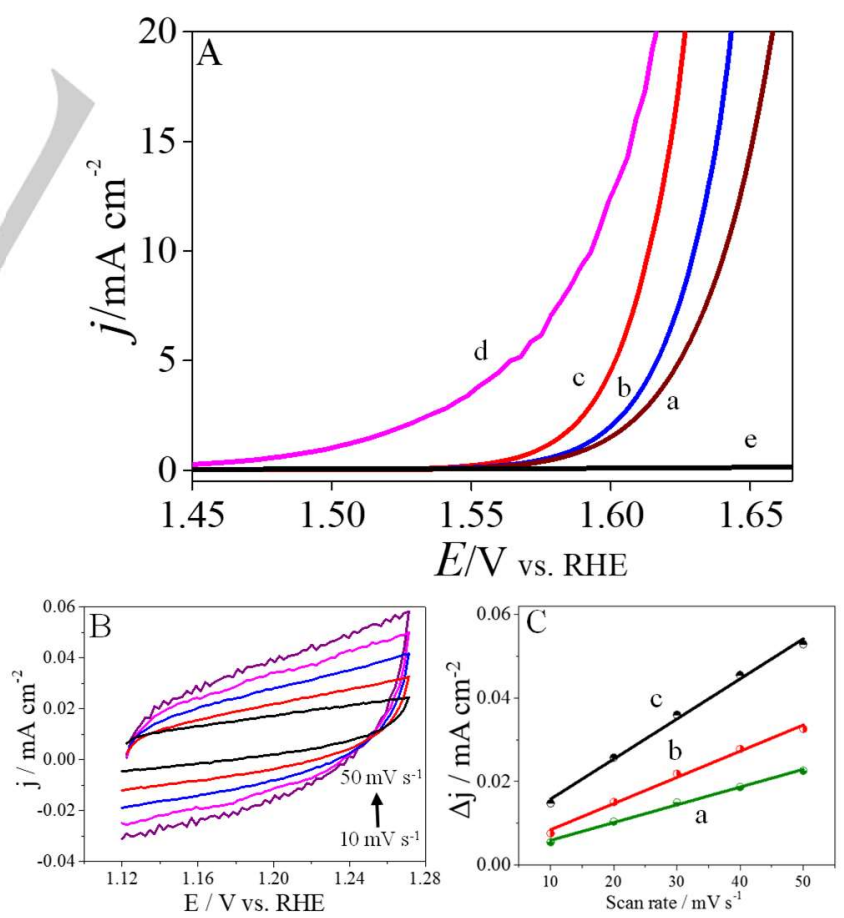

Figure 5. Electrochemical performance and electrochemical double layer capacitance $\left(\mathrm{C}_{\mathrm{dl}}\right)$ of different size $\mathrm{CoFe}_{2} \mathrm{O}_{4}$ nanoparticles for OER activity in 1 $\mathrm{M} \mathrm{KOH}$ solution. (A) Linear sweep voltammetry curves of a) $5.9 \mathrm{~nm}$; b) $4.5 \mathrm{~nm}$; C) $3.1 \mathrm{~nm} \mathrm{CoFe} \mathrm{O}_{4}$ nanoparticles d) commercial $\mathrm{IrO}_{2}$ and e) bare GCE towards OER activity in $1 \mathrm{M} \mathrm{KOH}$ solution. (B) $\mathrm{CV}$ curves of $3.1 \mathrm{~nm} \mathrm{CoFe} \mathrm{CO}_{4}$ nanoparticles with different scan rates. (C) Charging current density differences 
as the function of scan rates for a) $5.9 \mathrm{~nm}$; b) $4.5 \mathrm{~nm}$; c) $3.1 \mathrm{~nm} \mathrm{CoFe}_{2} \mathrm{O}_{4}$ nanoparticles.

Summarizing the complementary characterization results obtained by XRD, XPS, Mössbauer spectroscopy and electron microscopy, uniform and crystalline sub-10 nm cobalt ferrite particles of the spinel type have been successfully synthesized with varying sizes, compositions and cation distributions.

\section{OER activity}

The OER performance of $\mathrm{Co}_{x} \mathrm{Ni}_{1-x} \mathrm{Fe}_{2} \mathrm{O}_{4}$ nanoparticles with different sizes and compositions were measured using a common three electrode system in alkaline $1 \mathrm{M} \mathrm{KOH}$ solution.

Effect of particle size: Results for the OER activity of different sizes are shown in figure $5 \mathrm{~A}$ along with commercial $\mathrm{IrO}_{2}$ under similar loading. The OER response from LSVs of a bare glassy carbon is negligible, while the anodic current recorded on pure $\mathrm{CoFe}_{2} \mathrm{O}_{4}$ displays a sharp onset potential at about $1.56 \mathrm{~V}$ (Figure $5 \mathrm{~A})$. The over potential required to deliver a $10 \mathrm{~mA} \mathrm{~cm}^{-2}$ current density, that is estimated to be a suitable benchmark for a solar fuel production, is used as a convenient figure of merit to evaluate the OER activity. ${ }^{1 \mathrm{C}, 10}$ As shown in figure $5 \mathrm{~A}$, small nanoparticles $(3.1 \mathrm{~nm})$ exhibit more negative onset potentials and potentials at $10 \mathrm{~mA} \mathrm{~cm}{ }^{-2}$ with higher current density than larger nanoparticles $(4.5,5.9 \mathrm{~nm})$, suggesting superior OER catalytic activity (table-1, $\mathrm{SI})$. However the activity is less as compared to Co-Fe, Ni-Fe layered double hydroxides reported in the literature. ${ }^{2 a}$
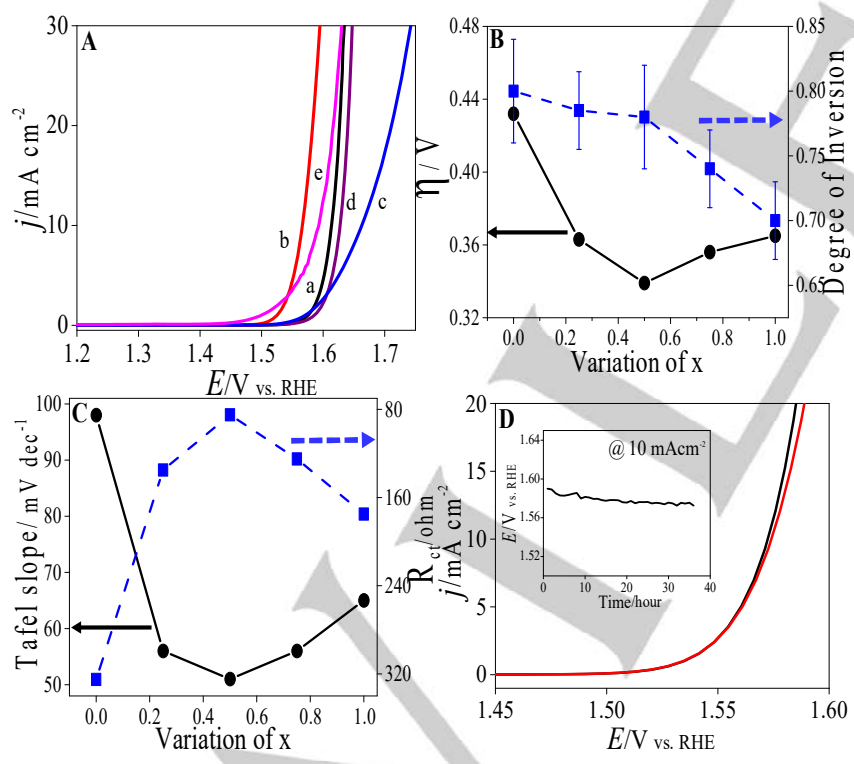

Figure 6. A) OER activity of (a) $\mathrm{CoFe}_{2} \mathrm{O}_{4}$; (b) $\mathrm{Co}_{0.5} \mathrm{Ni}_{0.5} \mathrm{Fe}_{2} \mathrm{O}_{4}$; (c) $\mathrm{NiFe}_{2} \mathrm{O}_{4}$; (d) physical mixture of $\mathrm{CoFe}_{2} \mathrm{O}_{4}, \mathrm{NiFe}_{2} \mathrm{O}_{4}$ nanoparticles and e) commercial $\mathrm{IrO}_{2}$. B) Effect of activity of $\mathrm{Co}_{x} \mathrm{Ni}_{01-x} \mathrm{Fe}_{2} \mathrm{O}_{4}$ as the function of inversion parameter. C) Tafel slope and EIS spectra recorded at an overpotential of $0.35 \vee$ for $\mathrm{Co}_{\times} \mathrm{Ni}_{1}$. ${ }_{x} \mathrm{Fe}_{2} \mathrm{O}_{4}$. D) Linear sweep voltammograms of $\mathrm{Co}_{0.5} \mathrm{Ni}_{0.5} \mathrm{Fe}_{2} \mathrm{O}_{4}$ before and after electrochemical potential cycling. Inset shows the stability at $10 \mathrm{~mA} \mathrm{~cm}^{-2}$ for 36 hours. Electrochemical cycling were recorded at $1600 \mathrm{rpm}$ and $5 \mathrm{mVs}^{-1}$ in $1 \mathrm{M}$ $\mathrm{KOH}$ solution before and after 1000 potential cycling of electrodes between 1.1 and $1.7 \mathrm{~V}$ at a scan rate of $50 \mathrm{mV} / \mathrm{sec}$.
High electrochemical surface area (ECSA) is the prerequisite for an electrocatalyst and we investigated the electrochemical double layer capacitance $\left(C_{\text {dl }}\right)$ of the differently sized nanoparticles by simple cyclic voltammetry method ${ }^{14}$ (Figure $5 B$ and figure $S 11$, $\mathrm{SI})$. It is clear from figure $5 \mathrm{C}$ that the slope for charging current of $3.1 \mathrm{~nm} \mathrm{CoFe} \mathrm{O}_{4}$ is $9.59 \times 10^{-4}$, which is 1.52 and 2.25 times higher than $\left(6.27 \times 10^{-4}\right) 4.5 \mathrm{~nm}$ and $5.9 \mathrm{~nm}\left(4.25 \times 10^{-4}\right) \mathrm{CoFe}_{2} \mathrm{O}_{4}$ nanoparticles, respectively. These factors and their relative difference are comparable, though slightly larger, to the difference expected in geometrical surface area between the samples assuming spherical shape of the particles (factors of 1.3 and 1.8). The size dependent activity of noble metal nanostructures is well known, ${ }^{15}$ while a comparable effect of transition metal chalcogenides has been reported less frequently. $\mathrm{MoS}_{2}$ and $\mathrm{Co}_{3} \mathrm{O}_{4}$ nanoparticles were found to exhibit an enhanced activity with decreasing particle size, mainly attributed to the presence of abundant edges and large surface area. ${ }^{16}$ From the good scaling of the ECSA with the calculated specific geometric surface areas, it can be estimated that the major contribution to the improved activity is due to the more favorable surface-to-bulk ratio of smaller particles, while a contribution of different surface terminations or special sites in smaller particle cannot be completely ruled out, but seems not dominant in the size range investigated here.

Effect of composition: Further, the properties of ferrite nanostructures are very sensitive to variations of the composition and addition of other metals, especially for magnetization. ${ }^{9}$ Figure $6 \mathrm{~A}$ shows the OER catalytic activities of $\mathrm{Co}_{x} \mathrm{Ni}_{1-x} \mathrm{Fe}_{2} \mathrm{O}_{4}$ all having particle sizes close to $\sim 5 \mathrm{~nm}$ (Table $1, \mathrm{SI}$ ). The catalytic activity is substantially improved for $\mathrm{Co}_{0.5} \mathrm{Ni}_{0.5} \mathrm{Fe}_{2} \mathrm{O}_{4}$ as compared to pure $\mathrm{CoFe}_{2} \mathrm{O}_{4}, \mathrm{NiFe}_{2} \mathrm{O}_{4}$ and their physical mixture. The enormous difference between physical mixture and the single-phase $\mathrm{Co}_{x} \mathrm{Ni}_{1}$ ${ }_{x} \mathrm{Fe}_{2} \mathrm{O}_{4}$ nanoparticles confirms that the synergetic effect of $\mathrm{Co}$ and $\mathrm{Ni}$ is related to a mixed cationic sub-lattice in the spinel structure. In our study of different $\mathrm{Co}$ : Ni ratios in $\mathrm{Co}_{x} \mathrm{Ni}_{1-x} \mathrm{Fe}_{2} \mathrm{O}_{4}$ with $\mathrm{x}=0.25$, 0.5, 0.75, the optimal Co:Ni ratio was achieved at $\mathrm{x}=0.5$ (Figure $6 \mathrm{~B}, \mathrm{C}$ and $\mathrm{S} 12, \mathrm{SI}$ ). Importantly, $\mathrm{Co}_{0.5} \mathrm{Ni}_{0.5} \mathrm{Fe}_{2} \mathrm{O}_{4}$ shows an overpotential of $341 \mathrm{mV}$ at $10 \mathrm{~mA} \mathrm{~cm}{ }^{-2}$, which is comparable to that of the $\mathrm{IrO}_{2}$ benchmark $(363 \mathrm{mV})$. The improved activity in the solid solution may be due to the different surface composition and/or changes in the intrinsic electronic conductivity. Interestingly, this most active composition coincides with the sample that reaches saturation in the degree of structural inversion upon partial substitution of $\mathrm{Co}$ with $\mathrm{Ni}$ with only moderate increase for higher $\mathrm{Ni}$ contents (Figure 6B). This parameter determines the distribution of not only $\mathrm{Fe}^{3+}$, but also of $\mathrm{Co}^{2+}$ and $\mathrm{Ni}^{2+}$ over the tetrahedral and octahedral sites. However, an increase from 0.70 in $\mathrm{CoFe}_{2} \mathrm{O}_{4}$ to 0.78 in $\mathrm{Ni}_{0.5} \mathrm{Co}_{0.5} \mathrm{Fe}_{2} \mathrm{O}_{4}$ means that the relative amount of $\mathrm{Fe}^{3+}$ on tetrahedral sites increases with substitution only from $36 \%$ to $39 \%$ of the total iron content. As the Ni content is further increased, no large change is observed in the cation distribution, but the predominantly octahedral $\mathrm{Co}^{2+}$ sub-lattice is gradually diluted with $\mathrm{Ni}^{2+}$, while the OER activity shrinks. This result may be seen as an indication that tetrahedral Fe sites and/or octahedral Co sites play an important role for the OER on cobalt ferrites catalysis. The role of the distinct coordination of $\mathrm{Co}, \mathrm{Ni}$ and $\mathrm{Fe}$ in spinels or related materials is 
discussed in the literature and support for a decisive role of tetrahedral and octahedral cobalt sites can be found. ${ }^{17}$ However, in our materials the relative changes in cation distribution are small compared to the changes in composition and it remains unclear if this trend in inversion parameter can solely explain the substantial differences in OER performance. Furthermore, it is noted that the cobalt oxidation state at the surface will change from (II) to (III) under OER conditions (see below), which will induce further changes in the coordination of Co. Furthermore, a hydroxylation of the surface under working conditions can be expected. Thus, a direct correlation of the structural features of the pre-catalyst investigated here by Mössbauer spectroscopy with the true working conditions has to be looked at with care.

Further studies of the electrode kinetics of the catalytic processes, showed that the mixed cationic sub-lattice in $\mathrm{Co}_{0.5} \mathrm{Ni}_{0.5} \mathrm{Fe}_{2} \mathrm{O}_{4}$ not only results in a lower potential but also in a lower Tafel slope of $51 \mathrm{mV} \mathrm{dec}^{-1}$ compared to pure $\mathrm{CoFe}_{2} \mathrm{O}_{4}\left(65 \mathrm{mV} \mathrm{dec}^{-1}\right)$ and $\mathrm{NiFe}_{2} \mathrm{O}_{4}\left(98 \mathrm{mV} \mathrm{dec}{ }^{-1}\right)$ indicating more facile electron transport through the electrode (Figure $6 \mathrm{C}$ and $\mathrm{S} 13, \mathrm{SI}$ ). Electrochemical impedance spectroscopy (EIS) was recorded at an overpotential of $350 \mathrm{mV}$ and the results are shown in Figure $6 \mathrm{C}$ and $\mathrm{S} 13$ (SI). The charge transfer resistance $\left(R_{\mathrm{ct}}\right)$ is significantly lower for $\mathrm{Co}_{0.5} \mathrm{Ni}_{0.5} \mathrm{Fe}_{2} \mathrm{O}_{4}$ ( $\left.\sim 85 \mathrm{ohm}\right)$ compared to pure $\mathrm{CoFe}{ }_{2} \mathrm{O}_{4}(\sim 175$ ohm) and $\mathrm{NiFe}_{2} \mathrm{O}_{4}(\sim 325 \mathrm{ohm})$ nanoparticles, which reveals its efficient electron transport in the electrocatalytic process for the OER. Thus in addition and possibly in excess to the structural effect discussed above, introduction of $\mathrm{Ni}$ in cobalt ferrite crystals also improves both the electrical conductivity and promotes the efficient electron transport, leading to an acceleration of charge transport by shortening ion diffusion paths and the fast adsorption of $\mathrm{H}_{2} \mathrm{O}$ molecules. The integration of facile electron transport with lower Tafel slope can thus give rise to the very favorable kinetics for the OER of $\mathrm{Co}_{0.5} \mathrm{Ni}_{0.5} \mathrm{Fe}_{2} \mathrm{O}_{4}$ nanoparticles. In addition, $\mathrm{Co}_{0.5} \mathrm{Ni}_{0.5} \mathrm{Fe}_{2} \mathrm{O}_{4}$ nanoparticles also favor the electrochemical oxidation of $\mathrm{Co}(\mathrm{II})$ to $\mathrm{Co}(\mathrm{III})$, which occurs at a lower oxidation potential compared to $\mathrm{CoFe}_{2} \mathrm{O}_{4}$, as shown in Figure $\mathrm{S} 14$ (SI).

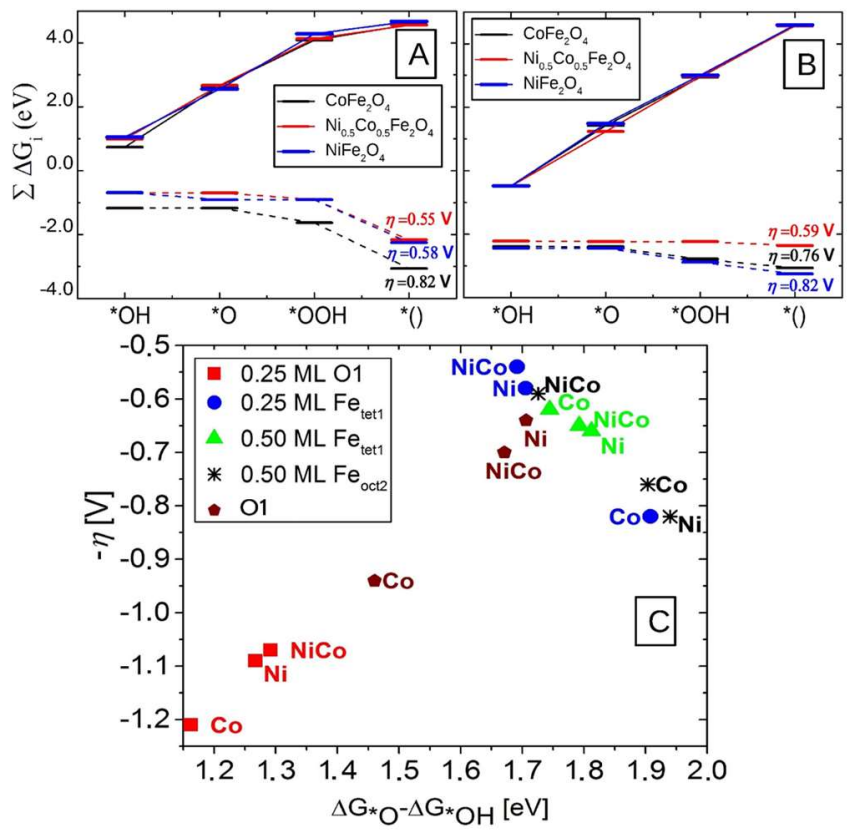

Figure 7. A, B) Cumulative reaction free energies from the $\mathrm{DFT}+\mathrm{U}$ calculations for the reaction intermediates at the $0.25 \mathrm{ML} \mathrm{Fe} e_{\text {tet1 }}$ and $0.50 \mathrm{ML} \mathrm{Fe}_{\text {oct2 }}$ terminations of $\mathrm{Co}_{x} \mathrm{Ni}_{(1-\mathrm{x})} \mathrm{Fe}_{2} \mathrm{O}_{4}$ (111) with $\mathrm{x}=0.0$ (blue), 0.5 (red) and 1.0 (black) C) The negative overpotential of $\mathrm{Co}_{x} \mathrm{Ni}_{(1-x)} \mathrm{Fe}_{2} \mathrm{O}_{4}$ against binding energy differences of $\Delta \mathrm{G}^{*} \mathrm{O}-\Delta \mathrm{G}{ }^{*} \mathrm{OH}$ for different terminations and reaction sites.

The experimental electrochemical results clearly show that partial substitution in the cationic sub-lattice of cobalt ferrite spinels and the intimate chemical and electronic coupling between the cations can lead to multiple and complex modifications that still need to be understood on an atomic level.

Computational Results: To gain further insight into this synergistic effect, DFT $+U$ calculations were performed on $\mathrm{Co}_{x} \mathrm{Ni}_{1}$ ${ }_{x} \mathrm{Fe}_{2} \mathrm{O}_{4}$. Several terminations were chosen: with an oxygen layer upon the octahedral $\mathrm{Co}_{1-\mathrm{x}} \mathrm{Ni}_{\mathrm{x}}$ layer $\left(\mathrm{O}_{1}\right)$, with an additional $0.25 \mathrm{ML}$ tetrahedral iron $\left(0.25 \mathrm{ML} \mathrm{Fe} e_{\text {tet1 }}\right)$ which has two reaction sites $\mathrm{Fe}_{\text {tet1 }}$ and $\mathrm{O}_{1}$, and with a further $0.25 \mathrm{ML}$ of octahedral $\mathrm{Fe}\left(0.5 \mathrm{ML} \mathrm{Fe} \mathrm{oct2}_{\text {- }}\right.$ tet1) with $\mathrm{Fe}_{\mathrm{oct} 2}$ and $\mathrm{Fe}_{\text {tet1 }}$ as reaction sites. These terminations have been shown to be stable at the $\mathrm{NiFe}_{2} \mathrm{O}_{4}(111)$ surface under the accessible range of oxygen chemical potentials. ${ }^{18}$ According to Rossmeissl et al. ${ }^{1 \mathrm{a}}$ the water oxidation mechanism can be divided in four elementary steps:
A) ${ }^{*}+\mathrm{H}_{2} \mathrm{O} \rightarrow{ }^{*} \mathrm{OH}+\mathrm{H}^{+}+\mathrm{e}$
B) ${ }^{*} \mathrm{OH} \rightarrow{ }^{*} \mathrm{O}+\mathrm{H}^{+}+\mathrm{e}^{-}$
C) ${ }^{*} \mathrm{O}+\mathrm{H}_{2} \mathrm{O} \rightarrow{ }^{*} \mathrm{OOH}+\mathrm{H}^{+}+\mathrm{e}^{-}$
D) ${ }^{*} \mathrm{OOH} \rightarrow{ }^{*}+\mathrm{O}_{2}+\mathrm{H}^{+}+\mathrm{e}^{-}$

where ${ }^{*} \mathrm{OOH},{ }^{*} \mathrm{OH}$, and ${ }^{*} \mathrm{O}$ represent chemisorbed intermediate species on the surface denoted by *

Each reaction involves the coupled transfer of an electron to the electrode and a proton to water. The cumulative reaction free energies of the intermediate steps that occur during OER for 0.25 $\mathrm{ML} \mathrm{Fe}$ tet1 and $0.50 \mathrm{ML} \mathrm{Fe}$ oct2 terminations are shown in Figure 7A$\mathrm{B}$, Figure $\mathrm{S} 17-\mathrm{S} 18(\mathrm{SI})$. For both terminations the calculations confirm that $\mathrm{Co}_{0.5} \mathrm{Ni}_{0.5} \mathrm{Fe}_{2} \mathrm{O}_{4}(111)$ exhibits a lower overpotential than the pure $\mathrm{CoFe}_{2} \mathrm{O}_{4}(111)$ and $\mathrm{NiFe}_{2} \mathrm{O}_{4}(111)$ : it is 270 (170) $\mathrm{mV}$ lower than $\mathrm{CoFe}_{2} \mathrm{O}_{4}$ and 40 (230) $\mathrm{mV}$ lower than $\mathrm{NiFe}_{2} \mathrm{O} 4$ for the two terminations. Note that these values are lower than the ones reported for other transition metal oxides such as pure $\mathrm{Fe}_{2} \mathrm{O}_{3}(0001) .{ }^{18 \mathrm{e}}$ It is furthermore noted that the experimentally determined order in catalyst's performance within the substitution series agrees best with the theoretical results obtained on the $\mathrm{Fe}_{\text {oct2 }}$ termination. Consistent with the work of Calle-Vallejo et al. ${ }^{6 \mathrm{~d}}$ and Man et al., ${ }^{18 d}$ Figure $7 \mathrm{c}$ shows that the lowest overpotential correlates with the optimum binding energy difference of $\Delta G^{*} \mathrm{O}$ $\Delta G^{*} \mathrm{OH}$ for different reaction sites. Thus the $\mathrm{DFT}+U$ results overall confirm that $\mathrm{CO}_{0.5} \mathrm{Ni}_{0.5} \mathrm{Fe}_{2} \mathrm{O}_{4}$ is more favorable for OER in agreement with our experimental findings.

Our study underpins the importance of the substitution effect for designing high performance electrode materials in electrocatalysis. It was shown for $\mathrm{Co}_{1-\mathrm{x}} \mathrm{Ni}_{\mathrm{x}} \mathrm{Fe}_{2} \mathrm{O}_{4}$ that substitution can be effective in changing the relative binding energies of the relevant ${ }^{*} \mathrm{O}$ and ${ }^{*} \mathrm{OH}$ intermediates thus facilitating the OER reaction. Different compositions of $\mathrm{CoFe}_{2} \mathrm{O}_{4}$ nanocrystals with other bivalent cations such as $\mathrm{Mn}^{2+}, \mathrm{Zn}^{2+}$ and $\mathrm{Fe}^{2+}$ were also synthesized and studied as OER catalysts (Figure S15-16, SI). Interestingly, an improved activity compared to pure $\mathrm{CoFe}_{2} \mathrm{O}_{4}$ was 
also observed for these substituent. While these systems unlike the $\mathrm{Co}_{1-\mathrm{x}} \mathrm{Ni}_{\mathrm{x}} \mathrm{Fe}_{2} \mathrm{O}_{4}$ have not been studied in great detail yet, this screening study suggests that cation substitution in spinels might be a general concept capable of improving base metal OER catalysts towards practical application in electrolyzers.

In practice, stability is one of the key factors in evaluating electrocatalyst performance. Notably, little appreciable change was observed for $\mathrm{Co}_{0.5} \mathrm{Ni}_{0.5} \mathrm{Fe}_{2} \mathrm{O}_{4}$ at $10 \mathrm{~mA} \mathrm{~cm}{ }^{-2}$ for almost 30 hours (Figure 6D). To assess the stability of $\mathrm{Co}_{0.5} \mathrm{Ni}_{0.5} \mathrm{Fe}_{2} \mathrm{O}_{4}$ and $\mathrm{CoFe}_{2} \mathrm{O}_{4}$ during OER, continuous cyclic voltammograms up to 1000 cycles were recorded. Figures 6D (inset) and figure S19 display LSV curves recorded at $5 \mathrm{mV} \mathrm{s}^{-1}$ for $\mathrm{Co}_{0.5} \mathrm{Ni}_{0.5} \mathrm{Fe}_{2} \mathrm{O}_{4}$ and $\mathrm{CoFe}_{2} \mathrm{O}_{4}$ before and after 1000 cycles between $1.1 \mathrm{~V}$ and $1.6 \mathrm{~V}$. Again, hardly any change was observed for $\mathrm{Co}_{0.5} \mathrm{Ni}_{0.5} \mathrm{Fe}_{2} \mathrm{O}_{4}$. In comparison, $\mathrm{CoFe}_{2} \mathrm{O}_{4}$ showed a lower stability. During potential cycling, nanoparticles become agglomerated as observed by TEM (figure S19, SI) resulting in significant loss of electrocatalytic activity, while the individual nanoparticles still be clearly seen. Figure $\mathrm{S} 19$ (SI) shows the XRD of $\mathrm{Co}_{0.5} \mathrm{Ni}_{0.5} \mathrm{Fe}_{2} \mathrm{O}_{4}$ after 1000 potential cycling and clearly seen that there is no change in phase composition after cycling (figure S19, SI).

\section{Conclusions}

In conclusion, a facile experimental protocol has been developed for synthesizing different sizes and compositions of cobalt ferritebased nanoparticles by a simple organic-solution phase method. It was shown for $\mathrm{CoFe}_{2} \mathrm{O}_{4}$ that a decreasing size of the spinel nanoparticles in the sub-10 $\mathrm{nm}$ range has a beneficial effect on the electrocatalytic activity in the oxygen evolution reaction. This effect is attributed to the increase in electrochemical surface area with decreasing particle size leading to enhanced anion exchangeability between the electrolyte and electrode. However, in the sub-10 $\mathrm{nm}$ range, the effect of isomorphous cation substitutions was even more noticeable. $D F T+U$ calculations showed that the beneficial effect of $\mathrm{Ni}$ substitution on the OER activity of $\mathrm{CoFe}_{2} \mathrm{O}_{4}$ was related to optimal relative binding strength of the reaction intermediates during water oxidation. Making use of this effect, the best sample of this study, $\mathrm{Co}_{0.5} \mathrm{Ni}_{0.5} \mathrm{Fe}_{2} \mathrm{O}_{4}$, turned out to be a highly active and stable OER catalyst.

\section{Experimental Section}

Experimental

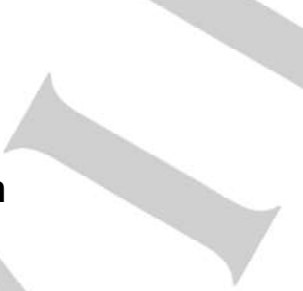

Materials: Metal acetylacetonates $\mathrm{M}(\mathrm{acac})_{2}(\mathrm{M}=\mathrm{Ni}, \mathrm{Co}, \mathrm{Mn}, \mathrm{Cu}, \mathrm{Zn})$ and $\mathrm{Fe}(\mathrm{acac})_{3}$ were purchased from Sigma-Aldrich and used without further purification. Oleylamine was obtained from Acros organics and was degassed prior to use. Commercial $\mathrm{IrO}_{2}$ was received from Sigma-Aldrich.

Synthesis of $\mathrm{Co}_{x} \mathrm{Ni}_{1-\mathrm{x}} \mathrm{Fe}_{2} \mathrm{O}_{4}$ nanoparticles: In a typical reaction, a mixture of $\mathrm{Fe}(\mathrm{acac})_{3}$ and $\mathrm{M}(\mathrm{acac})_{2}$ (2 mmol in total) were suspended in 15 $\mathrm{mL}$ of oleylamine. The mixtures were first heated to $100{ }^{\circ} \mathrm{C}$ for $10 \mathrm{~min}$ resulting in a clear red solution to remove low boiling solvents. Then the temperature was raised to $250^{\circ} \mathrm{C}$ and kept at that temperature for $60 \mathrm{~min}$. After the solution was cooled to ambient temperature, the nanoparticles were precipitated by adding $10 \mathrm{~mL}$ of ethanol. The precipitate was isolated by centrifugation, purified by repeated washing with 2-3 times of ethanol and dried in vacuum.

For the preparation of nanoparticles with different sizes, the final reaction mixture was refluxed at different reaction temperatures $\left(200^{\circ} \mathrm{C}, 250^{\circ} \mathrm{C}\right.$ and $300^{\circ} \mathrm{C}$ ) for $1 \mathrm{~h}$. Substituted spinel oxides were prepared simply by heating stoichiometric mixtures of the three different metal acetylacetonate complexes at $250^{\circ} \mathrm{C}$ for $1 \mathrm{~h}$.

Structural Characterization: Powder X-ray diffraction (XRD) patterns of nanoparticles were recorded at ambient temperature $\left(25 \pm 2{ }^{\circ} \mathrm{C}\right)$ using a Bruker D8 Advance powder diffractometer in Bragg-Brentano mode with $\mathrm{Cu}$ Ka radiation $(\lambda=1.5418 \AA, 40 \mathrm{kV}$ and $40 \mathrm{~mA})$. The powder samples were investigated in the range of 5 to $90^{\circ} 2 \theta$ with a step size of $0.01^{\circ}$ and a counting time of $0.3 \mathrm{~s}$. The size and morphology of the nanostructures were characterized by using a JEOL 2010 (200 kv) transmission electron microscope. Energy-dispersive X-ray spectroscopy (EDS) studies were carried out on a scanning electron microscope (Jeol JSM 6510) equipped with an energy-dispersive X-ray spectroscopy (EDX) device (Bruker Quantax 400). The obtained spectra were quantified using the software Esprit 1.9 (Bruker). X-ray photo electron spectroscopy (XPS) was recorded using Versaprobe IIM $^{\mathrm{TM}}$ by ULVAC-Phi with a small minimal beam size of < $10 \mu \mathrm{m}$ having spectral resolution of $0.5 \mathrm{eV}$. Infrared spectroscopy (IR) spectra were recorded with an ALPHA-T FT-IR spectrometer equipped with a single-reflection ATR sampling module. Thermogravimetric analysis (TGA) was performed using a Mettler Toledo TGA/DSC 1 Star System in argon atmosphere and a heating rate of $20 \mathrm{~K} / \mathrm{min}$.

Electrochemical Characterization: All electrochemical measurements were performed in a conventional three-electrode cell using an Autolab potentiostat/galvanostat (PGSTAT12, Eco Chemie, Utrecht, The Netherlands) coupled to a Metrohm RDE rotator. Disc shaped glassy carbon of geometric area $0.126 \mathrm{~cm}^{2}$, modified with the catalysts used as the working electrode, $\mathrm{Ag} / \mathrm{AgCl} / 3 \mathrm{M} \mathrm{KCl}$ as the reference electrode and a platinum mesh as counter electrode. The measured potentials were converted to the reversible hydrogen electrode (RHE) scale using the following equation $\mathrm{E}_{\mathrm{RHE}}=\mathrm{E}_{\mathrm{Ag} / \mathrm{AgCl}}+0.210 \mathrm{~V}+0.059 \mathrm{pH}$. The $\mathrm{pH}$ value was determined (using a pH meter) and was 14 for $1 \mathrm{M} \mathrm{KOH}$. Prior to the experiments, the glassy carbon electrode was polished on a polishing cloth using different alumina pastes $(3.0-0.05 \mu \mathrm{m})$ to obtain a mirror-like surface, followed by ultrasonic cleaning in water. For electrochemical measurements the catalyst ink was prepared by dispersing $5.0 \mathrm{mg} / \mathrm{mL}$ of the catalyst in ethanol water mixture (1:1) and ultrasonicated for $30 \mathrm{~min}$. $5.0 \mu \mathrm{L}$ of the catalyst suspension with a mass loading of $0.35 \mathrm{mg} / \mathrm{cm}^{2}$ was drop coated onto the polished glassy carbon electrode and dried in air at room temperature. Before the OER measurements, modified electrodes were subjected to continuous potential cycling in the potential window of $0.1 \mathrm{~V}$ to $1.1 \mathrm{~V}$ vs RHE until reproducible voltammograms were obtained. Electrochemical impedance spectroscopy was then recorded in the frequency range from $50 \mathrm{kHz}$ to $1 \mathrm{~Hz}$ at the corresponding open circuit potential of the electrode, using an $\mathrm{AC}$ perturbation of $10 \mathrm{mV}$. The resistance of the solution was determined from the resulting Nyquist plot, and the later used for ohmic drop correction according to the relation, $E_{c}=$ $E_{m}-i R_{s}$, where $E_{c}$ is the corrected potential and $E m$ is the applied potential. All reported current densities were calculated using the geometric surface area of the electrode.

DFT calculations: The density-functional theory (DFT) calculations were carried out both for bulk spinel's and surface reactivity using the VASP $\operatorname{code}^{18}$ that employs projector-augmented waves (PAW) ${ }^{19}$ and pseudopotentials. The generalized-gradient approximation (GGA) ${ }^{20}$ for the exchange-correlation functional was adopted together with an on-site Hubbard $U$ term at the transition metal cation sites. ${ }^{21}$ For more details on the calculations (see $\mathrm{SI}$ ).

\section{Acknowledgements}


This work was supported by the DFG within the SPP 1613, SPP 1681 and FOR 1509. RP and $\mathrm{HH}$ also acknowledge the allocation of computational time at the Leibnitz Rechenzentrum (grant pr87ro) and at magnitUDE of the Center of Computer Science and Simulation (DFG grant INST 20876/209-1 FUGG). Claudia Weidenthaler (Max-Planck-Institut für Kohlenforschung, Mülheim a.d.R., Germany) and the DFG core facility ICAN are gratefully acknowledged for performing the in-situ XRD and XPS experiments, respectively.

Keywords: spinel ferrites nanocrystals• electrocatalysis • oxygen evolution reaction $\cdot$ composition - DFT calculations

[1] a) J. Rossmeisl, Z.-W. Qu, H. Zhu, G.-J. Kroes, and J. K. Nørskov, J. Electroanal. Chem. 2007, 607, 83-89; b) M. G. Walter, E. L. Warren, J. R. McKone, S. W. Boettcher, Q. Mi, E. A. Santori, N. S. Lewis, Chem Rev. 2010, 110, 6446-6473; c) C. C. L. McCrory, S. Jung, J. C. Peters T. F. Jaramillo, J. Am. Chem. Soc. 2013, 135, 16977-16987.

[2] a) F. Song, X. Hu, Nat. Commun. 2014, 5, 4477; b) X. Long, J. Li, S. Xiao, K. Yan, Z. Wang, H. Chen, S. Yang, Angew. Chem. Int. Ed. 2014, 53 7584-7588; Angew. Chem. 2014, 126, 7714-7718; c) T. Y. Ma, S. Dai M. Jaroniec, S. Z. Qiao, Chem. Eur J. 2014, 20, 12669-12676.

[3] a) R. D. L. Smith, M. S. Prévot, R. D. Fagan, S. Trudel, C. P. Berlinguette, J. Am. Chem. Soc. 2013, 135, 11580-11586; b) J. Li, M. Zou, W. Wen Y. Zhao, Y. Lin, L. Chen, H. Lai, L. Guan, Z. Huang, J. Mater. Chem. A 2014, 2, 10257-10262; c) A. Bergmann, E. Martinez-Moreno, D. Teschner, P.Chernev, M. Gliech, J. Ferreira de Araujo, T. Reier, H. Dau, P. Strasser, Nat. Commun. 2015, 6, 8625; d) P. W. Menezes, A. Indra N. R. Sahraie, A. Bergmann, P. Strasser, M. Driess, Chem. Sus. Chem. 2015, 8, 164-171.

[4] a) T. N. Lambert, J. A. Vigil, S. E. White, D. J. Davis, S. J. Limmer, P. D. Burton, E. N. Coker, T. E. Beechem, M. T. Brumbach, Chem. Commun. 2015, 51, 9511-9514; b) X. J. Liu, Z. Chang, L. Luo, T. H. Xu, X. D. Lei, J. F. Liu, X. M. Sun, Chem. Mater. 2014, 26, 1889-1895; c) Y. Liang, Y. G. Li, H. L. Wang, J. G. Zhou, J. Wang, T. Regier; H. J. Dai, Nat. Mater 2011, 10, 780-786;

[5] a) T. Maiyalagan, K. A. Jarvis, S. Therese, P. J. Ferreira, A. Manthiram, Nat. Commun. 2014, 5, 3949; b) F. Cheng, J. Shen, B. Peng, Y. Pan, Z. Tao, J. Chen, Nat. Chem. 2011, 3, 79-84; c) L. Zhou, D. Zhao, X. W. Lou, Adv. Mater. 2012, 24, 745-748; d) Y. Liang, H. Wang, J. Zhou, Y. Li, J. Wang, T. Regier, H. Dai, J. Am. Chem. Soc. 2012, 134, 3517-3523.

[6] a) R. D. Smith, M. S. Prevot, R. D. Fagan, Z. Zhang, P. A. Sedach, M K. J. Siu, S. Trudel; C. P. Berlinguette, Science 2013, 340, 60-63; b) J. Landon, E. Demeter, N. Inoglu, C. Keturakis, I. E. Wachs, R. Vasic, A. I. Frenkel, J. R. Kitchin, ACS Catal. 2012, 2, 1793-1801; c) K. Fominykh, P. Chernev, I. Zaharieva, J. Sicklinger, G. Stefanic, M. Doblinger, A. Muller, A. Pokharel, C. Scheu, T. Bein, D. Fattakhova-Rohlfing, ACS Nano 2015, 9, 5180-5188; d) F. Calle-Vallejo, O. A. Diaz-Morales, M. J. Kolb, M. T. M. Koper, ACS Catal. 2015, 5, 869-873; e) S. Zou, M. S. Burke, M. G. Kast, J. Fan, N. Danilovic, S. W. Boettcher, Chem. Mater. 2015, 27, 8011-8020.

[7] a) M. Li, Y. Xiong, X. Liu, X. Bo, Y. Zhang, C. Hana, L. Guo, Nanoscale 2015, 7, 8920-8930; b) S. Liu, W. Bian, Z. Yang, J. Tian, C. Jin, M. Shen, Z. Zhou, R. Yang, J. Mater. Chem. A 2014, 2, 18012-18017; c) W. Yan, W. Bian, C. Jin, J. H. Tian, R. Yang, Electrochim. Acta 2015, 177, 6572; d) W. Y. Bian, Z. R. Yang, P. Strasser, R. Z. Yang, J. Power Sources 2014, 250, 196-203.

[8] a) H. Zhu, S. Zhang, Y.-X. Huang, L. Wu, S. Sun, Nano. Lett. 2013, 13 , 2947-2951; b) C. Li, X. Han, F. Cheng, Y. Hu, C. Chen, J. Chen, Nat Commun. 2015, 6, 7345; c) T. W. Kim, M. A. Woo, M. Regis, K.-S. Choi, J. Phys. Chem. Lett. 2014, 5, 2370-2374; d) J. Bao, X. Zhang, B. Fan, J. Zhang, M. Zhou, W. Yang, X. Hu, H. Wang, B. Pan, Y. Xie, Angew. Chemie. Int. Ed. 2015, 54, 7399-7404; Angew. Chem. 2015, 127, 75077512; e) M. I. Godinho, M. A. Catarino, M. I. Pereira, M. H. Mendonc, F. M. Costa, Electrochim. Acta. 2002, 47, 4307-4314.
[9] a) D. Li, H. Yun, B. T. Diroll, V. V. T. Doan-Nguyen, J. M. Kikkawa, C. B. Murray, Chem. Mater. 2016, 28, 480-489; b) Y. Yu, A. Mendoza-Garcia B. Ning, S. Sun, Adv. Mater. 2013, 25, 3090-3094;

[10] G. Wu, J. Wang, W. Ding, Y. Nie, L. Li, X. Qi, S. Chen, Z. Wie, Angew. Chemie. Int. Ed. 2016, 55, 1340-1344; Angew. Chem. 2016, 128, 1362 1366.

[11] a) S. Mourdikoudis, L. M. Liz-Marzán, Chem. Mater. 2013, 25, 1465 1476; b) V. Georgiadou, C. Kokotidou, B. Le Droumaguet, B. Carbonnier, T. Choli-Papadopoulou, C. Dendrinou-Samara, Dalton Trans. 2014, 43, 6377-6388.

[12] a) M. Etier, Y. Gao, V. V. Shvartsman, A. Elsukova, J. Landers, H. Wende, D. C. Lupascu, Ferroelectrics 2012, 438, 115-122; b) G. A. Sawatzky, F. van der Woude, A. H. Morrish, Phys. Rev. 1969, 183, 383-386; c) D. Carta, M. F. Casula, A. Falqui, D. Loche, G. Mountjoy, C. Sangregorio, A. Corrias, J. Phys. Chem. C 2009, 113, 8606-8615; d) D. Fritsch, C. Ederer, Appl. Phys. Lett. 2011, 99, 081916

[13] a) S. Diodati, L. Pandolfo, A. Caneschi, S. Gialanella, S. Gross, Nano Research. 2014, 7, 1027-1042; b) S. X. Zhang, H. Y. Niu, Y. Q. Cai, X L. Zhao, Y. L. Shi, Chem. Eng. J. 2010, 158, 599-607; c) V. K. Mittal, P. Chandramohan, S. Bera, M. P. Srinivasan, S. Velmurugan, S. V. Narasimhan, Solid State Commun. 2006, 137, 6-10.

[14] a) K. Gong, F. Du, Z. Xia, M. Durstock, L. Dai, Science 2009, 323, 760 764; b) M. A. Lukowski, A. S. Daniel, F. Meng, A. Forticaux, L. Li, S. Jin J. Am. Chem. Soc. 2013, 135, 10274-10277; c) J. Xie, J. Zhang, S. Li, F. Grote, X. Zhang, H. Zhang, R. Wang, Y. Lei, B. Pan, Y. Xie, J. Am Chem. Soc. 2013, 135, 17881-17888; d) J. Xie, H. Zhang, S. Li, R. Wang, X. Sun, M. Zhou, J. Zhou, X. Wen, Y. Xie, Adv. Mater. 2013, 25, 58075813.

[15] a) M. Shao, A. Peles, K. Shoemaker, Nano. Lett. 2011, 11, 3714-3719, b) A. Chen; C. Ostrom, Chem. Rev. 2015, 115, 11999-12044.

[16] a) T. Wang, D. Gao, J. Zhuo, Z. Zhu, P. Papakonstantinou, Y. Li, M. Li, Chem. Eur J. 2013, 19, 11939-11948; b) H. S. Jeon, A. Nugroho, J. Kim, H. Kim, B. K. Min, Int. J. Hydrogen Energy 2011, 36, 10587-10592.

[17] a) C. G. Morales-Guio, L. Liardet, X. Hu, J. Am. Chem. Soc. 2016, 138 8946-8957; b) L. J. Enmann, M. S. Burke, A. S. Batchellor, S. W. Boettcher, ACS Catal. 2016, 6, 2416-2423; c) B. Zhang et al., Science 2016, 352, 333-337.

[18] a) M. Isasa, A. Bedoya-Pinto, S. Vélez, F. Golmar, F. Sánchez, L. E. Hueso, J. Fontcuberta and F. Casanova, Appl. Phys. Lett. 2014, 105, 142402; b) G. Kresse, D. Joubert, Phys. Rev. B 1999, 59, 558-561; c) G. Kresse, J. Furthmüller, Phys. Rev. B 1996, 54, 11169-11186; d) I. C. Man, H. Y. Su, F. Calle-Vallejo, H. A. Hansen, J. I. Martínez, N. G, Inoglu, J. Kitchin, T. F. Jaramillo, J. K. Nørskov, J. Rossmeisl, ChemCatChem 2011, 3, 1159-1165: e) M. T. Nguyen, S. Piccinin, N. Seriani, and R. Gebauer, ACS Catal. 2015, 5, 2, 715-721.

[19] a) G. Kresse, D. Joubert, Phys. Rev. B 1999, 59, 558-561; b) G. Kresse J. Furthmüller, Phys. Rev. B 1996, 54, 11169-11186.

[20] J. P. Perdew, K. Burke, M. Ernzerhof, Phys. Rev. Lett. 1996, 77, 38653868.

[21] S. L. Dudarev, G. A. Botton, S. Y. Savrasov, C. J. Humphreys, A. P. Sutton, Phys. Rev. B 1998, 57, 1505-1509. 
Entry for the Table of Contents (Please choose one layout)

Layout 1:

\section{FULL PAPER}

Experimental and theoretical findings show that $\mathrm{Co}_{x} \mathrm{Ni}_{1-\mathrm{x}} \mathrm{Fe}_{2} \mathrm{O}_{4}$ nanoparticles have lower binding energies differences of $\mathrm{O}$ and $\mathrm{OH}$ as well as high intrinsic electrical conductivity with structural inversion, leading to favorable OER activity compared to pure $\mathrm{CoFe}_{2} \mathrm{O}_{4}$ and $\mathrm{NiFe}_{2} \mathrm{O}_{4}$ as well as their physical mixtures.

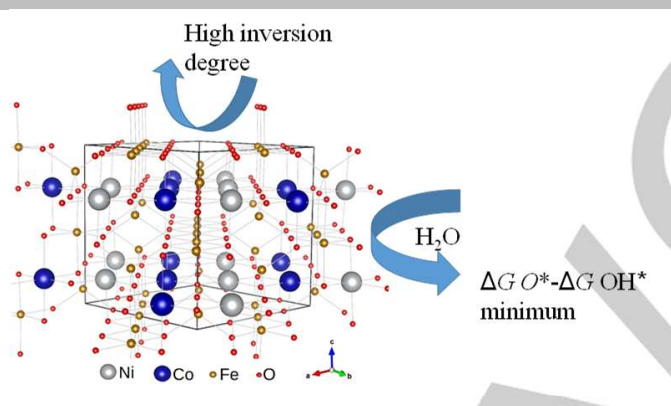

High inversion

$\Delta G O^{*}-\Delta G \mathrm{OH}^{*}$

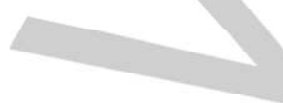

Kalapu Chakrapani, Georg Bendt, Hamidreja Hajiyani, Ingo

Schwarzrock, Thomas Lunkenbein, Soma Salamon, Joachim Landers, Heiko Wende, Robert Schlögl, Rossitza Pentcheva, Malte Behrens, * Stephan Schulz*

Role of Composition and Size of Cobalt Ferrite Nanocrystals in Oxygen Evolution Reaction 


\section{DuEPublico}

This text is made available via DuEPublico, the institutional repository of the University of Duisburg-Essen. This version may eventually differ from another version distributed by a commercial publisher.

DOI: $\quad 10.1002 /$ cctc. 201700376

URN: urn:nbn:de:hbz:464-20201210-163015-2

This is the peer reviewed version of the following article: ChemCatChem 2017, 9, 29882995, which has been published in final form at: https://doi.org/10.1002/cctc.201700376

All rights reserved. 